Ariza, J. G. (2015). Impacto sobre el bienestar social atribuido al fenómeno El Niño (ENOS) y al proceso de cambio climático. Un análisis sobre el mercado de energía colombiano. Revista Lebret (6). Bucaramanga, Colombia: Universidad Santo Tomás, pp. 61-86. ISSN 2145-5996.

\title{
Impacto sobre el bienestar social atribuido al fenómeno El Niño (ENOS) y al proceso de cambio climático. Un análisis sobre el mercado de energía colombiano*
}

\author{
Impact on social welfare attributed to El Niño phenomenon \\ (ENSO) and the process of climate change. An analysis of the \\ Colombian Energy Market
}

\begin{abstract}
José Guillermo Ariza Estévez
Resumen

Artículo que desarrolla y hace uso de un modelo de simulación del mercado de energía eléctrica colombiano, basado en el modelo teórico de Nash-Cournot, con el que se estimó el cambio en el bienestar de los consumidores, debido a la ocurrencia de eventos El Niño- Oscilación del Sur (ENOS) de importancia, como el de los años 1997-1998, así como por la posible ocurrencia de eventos de mayor intensidad, resultado del proceso de Cambio Climático. Las estimaciones obtenidas señalan que el evento del año 1997-1998, ocasionó pérdidas de bienestar de los consumidores por valor de \$1, 2 Billones de pesos (0.9\% del PIB-1998). De igual forma, eventos más intensos podrían ocasionar perdidas sobre el bienestar de entre el $0.36 \%$ y el $0.55 \%$ del PIB
\end{abstract}

\section{Palabras clave}

Modelo de Nash-Cournot, calentamiento global, valoración económica.

\section{Códigos de clasificación JEL: D43,D 62, Q54}

\begin{abstract}
This article develops and makes use of a simulation model of the Colombian electricity market, based on the theoretical model of Nash-Cournot, on which the change in consumer welfare was estimated, due to the occurrence of El Niño (ENSO) important events, such as those in 1997-1998, as well as the possible occurrence of events of greater intensity, a result of the climate change. The estimates obtained indicates that the event of the year 1997-1998, caused losses of consumer welfare of $\$ 1,2$ billion pesos $(0.9 \%$ of $1998-G D P)$. Similarly, more intense events may cause losses on the welfare of between $0.36 \%$ and $0.55 \%$ of GDP.
\end{abstract}

\section{Keywords}

Nash-Cournot model, global warming, economic valuation.

El artículo se deriva de la investigación: "Implicación económica del fenómeno El Niño ENOS. Aproximación desde el mercado de energía colombiano”, adelantada como Trabajo de Grado en el programa de Maestría en Economía del Medio Ambiente y los Recursos Naturales de la Universidad de los Andes, Colombia.

1 Magíster en Economía del Medio Ambiente y los Recursos Naturales. Docente Universidad de los Andes, Bogotá, Colombia. Correo electrónico: jo-ariza@uniandes.edu.co 


\section{Introducción}

El actual proceso de cambio climático acarrea una serie de efectos adversos sobre los ecosistemas naturales y las sociedades humanas, vía incrementos en la ocurrencia de eventos climatológicos extremos (IPCC, 2007).

Recientes investigaciones han establecido la relación existente entre este proceso y el aumento en la frecuencia, intensidad, duración y patrón de desarrollo de El Niño (ENOS). En Colombia, a este fenómeno se le responsabiliza de fuertes perturbaciones hidroclimáticas, manifiestas en la reducción de la precipitación promedio anual y en el aumento de la temperatura media mensual del aire.

En el caso del sector eléctrico y su mercado en particular, cualquier reducción en la precipitación y aumento de la temperatura, como resultado de la ocurrencia del fenómeno El Niño (ENOS) o su intensificación, posiblemente atribuido al proceso de "cambio climático", se traduce en disminuciones en los aportes hídricos al sistema y en la contracción de la participación de la generación hidráulica dentro de la oferta total de energía.

Un escenario como el anterior implicaría aumentos en el precio de la energía eléctrica y la consiguiente pérdida en el bienestar de los consumidores que participan de este mercado. Es de resaltar que dada la inelasticidad de la demanda de energía en el corto plazo y al carácter de mercado imperfecto, la posibilidad de transmisión de las pérdidas de bienestar que deberían ser asumidas por los productores (generadores) es alta. Esto conlleva que el impacto sobre el bienestar de los consumidores sea mayor que aquel que podría darse en mercados también expuestos a este tipo de eventos climáticos, pero en los que se observa cierto grado de competencia y de elasticidad en la demanda.

El presente trabajo se propuso como objetivo estimar el cambio en el bienestar de los consumidores que participan del mercado de energía colombiano, como resultado de la ocurrencia del evento El Niño (ENOS) registrado entre 1997 y 1998. Así mismo, cuantifica el cambio sobre el bienestar de estos agentes, como consecuencia de la ocurrencia de eventos El Niño (ENOS) de mayores niveles de intensidad, relacionados con la acentuación del proceso de calentamiento global o cambio climático. Las estimaciones conseguidas se constituyen en un insumo para posteriores análisis de evaluación de opciones de adaptación de este sector en particular, a riesgos asociados con la ocurrencia de este tipo de eventos o con la acentuación del proceso de calentamiento global o cambio climático.

Metodológicamente, el trabajo propone y hace uso de un modelo de simulación computacional del mercado de energía, diseñado a partir del modelo teórico de equilibrio oligopólico de Nash-Cournot, con el que es posible estimar medidas de bienestar marshallianas (Varian, 1998). La programación se realizó en lenguaje Visual Basic y recurre a la herramienta de optimización Solver que permite resolver 
modelos de optimización restringida. En la práctica, una vez conseguida la solución de equilibrio del mercado, relacionada con el escenario base (hidrología normal) y cada uno de los escenarios hidrológicos relacionados con El Niño, se procede a estimar las medidas clásicas de bienestar de productores (excedente del productor), junto a la variación de las mismas. Se aclara que dada la inelasticidad de la demanda de energía, el cambio en el bienestar de los consumidores se aproxima al cambio observado en el excedente de los productores. Finalmente, esta variación daría cuenta del impacto económico resultado de la ocurrencia del fenómeno El Niño (ENOS) y su posible intensificación dada la acentuación del proceso de "calentamiento global" o "cambio climático". Todo el análisis se aborda desde un enfoque de economía del bienestar aplicado al mercado de energía colombiano.

\section{Antecedentes}

\section{Fenómeno El Niño Oscilación del Sur (ENOS)}

El Niño Oscilación del Sur (ENOS) es un fenómeno de naturaleza marina y atmosférica, de carácter recurrente mas no periódico (IDEAM, 2002), causado por el aumento de la temperatura de las aguas superficiales del Océano Pacífico tropical, frente a las costas de Perú, Ecuador y sur de Colombia. Este es responsable de alteraciones climáticas y del régimen de lluvias a nivel regional, continental y global.

$\mathrm{Su}$ ocurrencia se da en intervalos temporales con amplitudes de entre 2 a 7 años y duraciones entre los 12 y los16 meses (IDEAM, 2006). El factor desencadenante es todavía incierto para la ciencia, sin embargo, se ha podido establecer que empieza su desarrollo durante la primavera del hemisferio norte (marzo-mayo), momento para el cual los vientos Alisios registran su menor intensidad.

Una vez desencadenado y al alcanzar su máximo desarrollo, ocasiona sequías intensas en Indonesia, Filipinas, Noreste de Australia, Noreste de Brasil, India, Sur África, España, América Central, Oeste de Canadá, como lluvias torrenciales e inundaciones en el Perú, Ecuador y oeste de los Estados Unidos, desde Texas a la Florida (UNAM, 2007).

En Colombia, los efectos hidroclimatológicos asociados con el evento se dan principalmente a nivel de disminución en la precipitación y en los caudales medios mensuales de las corrientes de agua, en los niveles de humedad del suelo y la actividad vegetal, así como en el aumento en la temperatura media del aire. Dichas alteraciones varían en grado e intensidad entre regiones geográficas y meses del año, además de relacionárseles directamente con efectos adversos sobre la producción agrícola y pecuaria, la producción de energía eléctrica y el transporte fluvial (Poveda, 2004).

Según reportes del IDEAM, en periodos de ocurrencia del evento, la temperatura en el territorio nacional tiende a aumentar entre 1.0 y $2.0^{\circ} \mathrm{C}$ por encima de los 
registros normales, mientras que las precipitaciones pueden disminuirse hasta en un $60 \%$ por debajo del promedio histórico (caso regiones Caribe, Andina y Orinoquía). Por otra parte, en la región Pacífica sur, la vertiente oriental de la cordillera Oriental y la Amazonía, El Niño (ENOS) ocasiona aumentos significativos en el volumen de lluvias ${ }^{2}$.

Es de mencionar que existe evidencia científica que señala que el fenómeno se encuentra influenciado directamente por eventos climatológicos de mayor escala como el proceso de "cambio climático" o "calentamiento global" (IPCC, 2007 y Trenberth, 1993). Esta hipótesis queda manifiesta al correlacionar los registros históricos que se tienen del evento y variables asociadas al proceso de "cambio climático" como la temperatura media global y los niveles de concentración de gases efecto invernadero. De acuerdo con lo anterior, se encuentra que para las últimas dos décadas (periodo en el que la emisión y concentración de gases efecto invernadero y el proceso de "calentamiento global" se ha incrementado), los eventos cálidos (El Niño) han predominado sobre las fríos (La Niña), además de ser estos los más calurosos, prolongados e intensos desde $1880^{3}$.

En este sentido, K. Trenberth y T. Hoar (1997) concluyen que el comportamiento observado del fenómeno "El Niño ENOS", en las dos décadas finales del siglo XX, es altamente inusual y debido probablemente a factores, como el "calentamiento global", que a su vez se asocia con el incremento de emisiones de gases de efecto invernadero de origen antropogénico.

A. Timmermann et al. (1999) tratan de verificar esta hipótesis, concluyendo que cambios importantes en la composición química de la atmósfera debido a aumentos en la concentración de dióxido de carbono $\mathrm{CO} 2$, junto a la profundización del proceso de calentamiento global, traen como consecuencia aumentos en las condiciones desencadenantes del fenómeno (aumento de la temperatura de la superficie del océano Pacífico ecuatorial y el debilitamiento de los vientos Alisios). Además, los modelos de simulación climáticos utilizados en su investigación evidenciaron un aumento en la frecuencia e intensidad del fenómeno del Niño (ENOS) bajo estas circunstancias ${ }^{4}$.

Por otra parte, L. Thompson (1993) sugiere que el registro de la variabilidad climática interanual preservada en los glaciales de la zona de Quelccaya, Perú y que habla de la ocurrencia, frecuencia e intensidad del fenómeno El Niño (ENOS) en un lapso aproximado de 1500 años, está altamente determinado por las tendencias que

2 En estas regiones se reportan aumentos cercanos al 20\% sobre el promedio histórico de precipitación (IDEAM, 2002, p. 7).

3 El Niño de 1982-1983 es el más fuerte registrado, el de 1990-1995 fue el más largo y el de 1997-1998 ha sido el más caliente. Por otra parte, el informe también advierte que "es muy probable que los años noventa hayan sido el decenio más cálido y 1998 el año más cálido, según los registros instrumentales existentes desde 1861" (IPCC, 2007).

4 Se estima que el $34 \%$ de los escenarios climatológicos futuros corresponderán a eventos niño, el $35 \%$ a eventos normales y el $31 \%$ a eventos niña. Estas probabilidades de ocurrencia se calcularon asumiendo las proyecciones de acumulación de gases efecto invernadero desarrolladas por el IPCC en 1992 (Timmermann, et al., 1999). 
han seguido las variables asociadas al clima mundial y que dan cuenta del proceso de "cambio climático".

\section{Impactos económicos asociados al fenómeno El Niño (ENOS) y al cambio climático}

Al fenómeno El Niño (ENOS) como al proceso de cambio climático, se les señala como los responsables de una serie de impactos de elevada magnitud sobre el medio ambiente y los sistemas socioeconómicos que se ubican en sus áreas de influencia. Dada la magnitud de estos, el interés de estimar su dimensión en términos económicos, para desde allí soportar la implementación de estrategias que busquen su mitigación (estrategias de reducción de emisión de GEI) o que permitan reducir los riesgos asociados, gracias a la ejecución de esquemas de adaptación.

En este sentido, el Banco Interamericano de Desarrollo (BID) y la Organización Meteorológica Mundial (OMM) estimaron, en el 2002, el impacto a nivel mundial atribuido al evento "El Niño (ENOS)" del periodo 1997-1998, el cual se caracteriza por ser uno de los más fuertes según los registros instrumentales. Concluyen estas organizaciones que los costos de este evento fueron cercanos a los US\$ 33 mil millones.

Así mismo, otros estudios cuantifican los costos derivados de la ocurrencia de estos fenómenos, pero sobre actividades económicas y áreas geográficas específicas, destacándose entre estos: O. Deschenes y M. Greenstone (2007) que estiman el impacto sobre los índices de mortalidad y los costos de adaptación de la población estadounidense a las nuevas condiciones climatológicas resultado del proceso de cambio climático. Esto a partir de la utilización de modelos de producción de salud y de sensibilidad del consumo. Los autores concluyen que al finalizar el siglo XXI y por causa del proceso de cambio climático, la tasa anual de mortalidad de los EE. UU. aumentará en un rango entre el $0.5 \%$ y el 1.7\%, mientras que el gasto energético residencial lo hará en un rango del $15 \%$ y el $30 \%$.

En Colombia, J. Bonilla, R. Rosales y H. Maldonado (2003) estimaron el valor económico de mejoras en la predicción del fenómeno El Niño (ENOS) en el sector azucarero colombiano. Dichos autores implementan para sus estimaciones un modelo estocástico de excedente económico, el cual les permitió concluir que la predicción perfecta de El Niño (ENOS) generaría beneficios económicos equivalentes al 1\% del PIB del sector azucarero para el 2000.

Adicionalmente, la Corporación Andina de Fomento CAF (2002) evaluó también para Colombia los daños ocasionados por el evento "El Niño (ENOS)" reportado entre 1997-1998, concluyendo que alcanzaron los US\$ 564 millones, de los cuales US\$ 56 millones correspondieron a daños directos (pérdida y reposición de acervo de capital), mientras que los restantes US\$ 502 millones hacen referencia a daños indirectos (mayores gastos incurridos, menores ingresos percibidos y producción agrícola que se ha dejado de obtener). Se recuerda que este evento en particular se 
consideró de intensidad fuerte pero más corto en duración que su antecesor de 19901991.

Nuevamente, O. Deschenes y M. Greenstone (2004) abordan el tema, cuantificando el impacto económico del cambio climático sobre los beneficios percibidos por el sector agrícola estadounidense. Recurren al empleo de un modelo de "datos panel" que relaciona los beneficios percibidos por el sector y variables asociadas al clima, con el que logran establecer que el proceso de cambio climático propiciará un incremento del $4 \%$ anual en los beneficios generados por este sector de la economía estadounidense.

De otro lado, son escasos, por no decir que nulos, análisis que pretendan indagar o estimar en términos económicos, los impactos que experimenta el sector hidrogenerador o los mercados de energía eléctrica, ante la ocurrencia de eventos climatológicos de esta naturaleza. Los pocos encontrados solo alcanzan a advertir sobre la vulnerabilidad del sector y el mercado ante la ocurrencia de fenómenos de esta clase (IIMI, 2007) o describen la relación entre reducciones en la disponibilidad del recurso hídrico y el efecto técnico derivado (IDEAM, 2002).

En cuanto al presente estudio, se aclara que este no pretende reproducir para el caso colombiano, alguno de los esfuerzos anteriormente presentados. Por su parte, lo que procura es cuantificar, desde un enfoque económico, el impacto sobre el bienestar de los agentes que participan del mercado de energía colombiano, debido a la ocurrencia de fenómenos El Niño (ENOS) de importancia histórica, como el evento de 1997-1998, o de posibles eventos de mayor intensidad resultado de la aceleración del proceso de cambio climático.

Metodológicamente, el trabajo se orienta a partir de un enfoque de economía del bienestar aplicado, basado en el examen de las variaciones de las medidas clásicas de bienestar (excedentes del productor y consumidor). Las estimaciones se consiguen a partir de la implementación y desarrollo de un modelo de simulación computacional del mercado de energía colombiano, fundamentado en el modelo teórico de equilibrio oligopólico de Nash-Cournot.

\section{Cambio climático, fenómeno El Niño (ENOS) y el mercado eléctrico colombiano}

El sector eléctrico se caracteriza por ser uno en el que se refleja en mayor medida los efectos ocasionados por el proceso de "cambio climático", vía alteraciones en la frecuencia e intensidad de fenómenos como El Niño (ENOS), que a su vez incide sobre el régimen de lluvias. Esta característica, para el caso colombiano, puede ser entendida si se repasa tanto la conformación tecnológica del parque generador existente, como la variabilidad en la disponibilidad del recurso hídrico ${ }^{5}$.

5 Dicha alteración estará determinada por las variaciones en las fases del ciclo hidrológico, las cuales son: la precipitación, la evaporación, la evapotranspiración, todas estas afectadas por el fenómeno. 
Figura 1. Impactos físico-climáticos y económicos atribuidos al proceso de cambio climático - ENOS y su intensificación

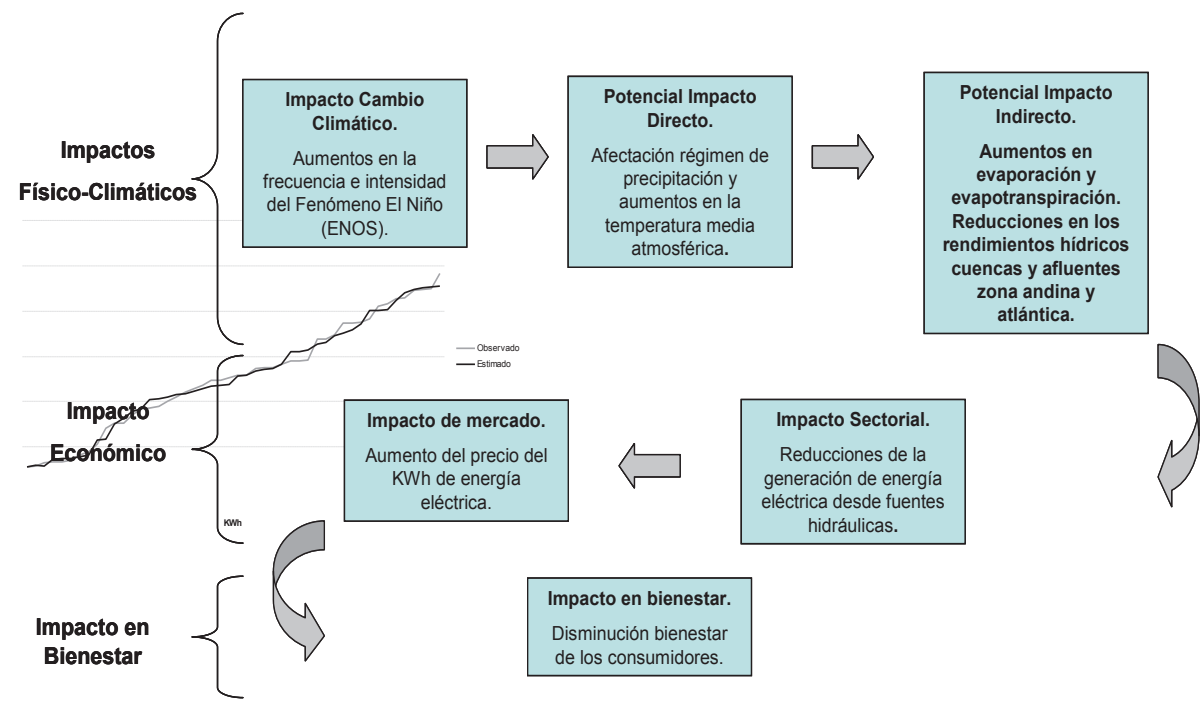

Fuente: autor.

En este sentido se puede decir que en Colombia existe actualmente una capacidad instalada de generación de energía eléctrica de 13,28 GW; de los cuales, 8,5 GW corresponde a tecnologías hidráulicas (67\% del total). Este alto componente hidráulico hace que el sistema nacional sea altamente vulnerable ante condiciones hidrológicas críticas (Pérez, 2004). En cuanto a la variabilidad del recurso hídrico, el IDEAM estima que en periodos de ocurrencia de eventos El Niño (ENOS) de intensidad normal, el promedio de reducción de los rendimientos de las cuencas colombianas puede ubicarse entre el 5\% y el 30\% (IDEAM, 2002). Sin embargo, estas reducciones pueden ser aún mayores, llegando incluso al $42 \%$, tal como sucedió en la primera estación seca del año 1998 (tabla 1). 
Tabla $1^{6}$. Variaciones promedio, rendimientos hidricos, afluentes sistema de embalse nacional. Por estaciones y promedio anual

\begin{tabular}{|cccccc}
\hline & \multicolumn{2}{c}{ Primer semestre } & \multicolumn{2}{c}{ Segundo semestre } & \multirow{2}{*}{$\begin{array}{c}\text { Variación } \\
\text { promedio } \\
\text { año }\end{array}$} \\
\cline { 2 - 4 } & Seca 1 & Lluvia 1 & Seca 2 & Lluvia 2 & $-10 \%$ \\
\hline 1998 & $-42 \%$ & $-14 \%$ & $20 \%$ & $-3 \%$ & $35 \%$ \\
\hline 2000 & $22 \%$ & $18 \%$ & $45 \%$ & $0 \%$ & $21 \%$ \\
\hline 2001 & $-13 \%$ & $-25 \%$ & $-6 \%$ & $-18 \%$ & $-16 \%$ \\
\hline 2002 & $-25 \%$ & $1 \%$ & $-4 \%$ & $-30 \%$ & $-14 \%$ \\
\hline 2003 & $-31 \%$ & $-9 \%$ & $-2 \%$ & $1 \%$ & $-10 \%$ \\
\hline 2004 & $-13 \%$ & $-5 \%$ & $10 \%$ & $8 \%$ & $0 \%$ \\
\hline 2005 & $5 \%$ & $0 \%$ & $-1 \%$ & $16 \%$ & $5 \%$ \\
\hline 2006 & $22 \%$ & $37 \%$ & $9 \%$ & $7 \%$ & $19 \%$ \\
\hline 2007 & $-9 \%$ & $26 \%$ & $29 \%$ & $27 \%$ & $18 \%$ \\
\hline 2008 & $36 \%$ & & & & \\
\hline
\end{tabular}

Rendimientos hídricos medidos en $\mathrm{m} 3 / \mathrm{seg}$.

Fuente: XM S.A E.S.P 7 .

Cabe recordar que una configuración del sector generador mayoritariamente hidráulica ( $78 \%$ de la capacidad de generación total de aquel momento), junto a la ocurrencia de un evento El Niño (ENOS) de carácter moderado, pero que excedió su tiempo normal de duración, ocasionó entre 1991 y 1992 el colapso del sistema de generación nacional y la implementación del más prolongado e intenso racionamiento de energía de la historia colombiana (Medina y Uribe, 2005). Esto como consecuencia de la imposibilidad del sector de generar $5183 \mathrm{GWh}$, lo que ocasionó la desatención del $14 \%$ de la demanda de aquel momento. Según fuentes gubernamentales, este racionamiento generó costos cercanos a los US\$35 millones semanales (Contraloría General de la República, ACOLGEN, 2003).

En cuanto a los mercados eléctricos o de energía en particular, cabe anotar que estos aparecen en todo el mundo, desde inicios y mediados de la década del noventa, tanto en economías desarrolladas como en desarrollo. En Colombia, el naciente mercado cobra génesis en el año 1994, con la expedición de las leyes 142 y 143,

6 Los afluentes aquí relacionados son: río Bata, río Calima, río Concepción, río Guavio, río Magdalena, ríos Miel, Nare, Negro y Cunday (Prado), río Grande, río Cauca (Salvajina) y Urra. Las variaciones se calculan relacionando el rendimiento total del afluente en el mes j del año "i", frente al aporte promedio del afluente en los meses j identificados como de hidrología normal.

$7 \mathrm{XM}$ es la empresa que administra el mercado de energía en Colombia. Es una sociedad anónima. En adelante XM S.A. E.S.P. 
fundamentadas en la búsqueda de la eficiencia, a partir de la creación de condiciones de competencia en las actividades de generación y comercialización y de monopolio regulado para la transmisión y distribución (UPME, 2004).

Dado lo anterior, se entenderá que la energía eléctrica en Colombia se "transa" mediante contratos bilaterales a largo plazo o transacciones comerciales entre agentes, efectuadas en la Bolsa de Energía, a precios definidos por las fuerzas del mercado (García y Arbeláez, 2002).

Al observar sus especificidades, se encuentra que dicho mercado reúne anualmente una demanda de $50467 \mathrm{GWh}$, como a una oferta (representada en términos de capacidad instalada de generación) de 13,28 GW, de los cuales 8,53 GW (64\%) corresponden a tecnologías hidráulicas. Es de mencionar que 7,82 GW de la capacidad instalada de generación hidráulica (92\%) son propiedad de tan solo 5 firmas generadoras, por lo que se puede decir que el sector generador reporta altos grados de concentración, catalogándosele como de oligopolio (tabla 2).

Tabla 2. Capacidad de generación por tipo de tecnología

\begin{tabular}{|lcc|}
\hline \multicolumn{1}{c}{ Unidades } & GW & Participación \\
\hline Térmicas & 4,30 & $32,4 \%$ \\
\hline Hidráulicas & 8,53 & $64,2 \%$ \\
\hline Térmicas menores & 0,02 & $0,2 \%$ \\
\hline Eólicas menores & 0,01 & $0,1 \%$ \\
\hline Hidráulicas menores & 0,42 & $3,2 \%$ \\
\hline Total & 13,28 & $100 \%$ \\
\hline
\end{tabular}

Fuente: XM S.A E.S.P.

Adicionalmente, al mercado lo caracteriza entre otras cosas, la existencia de un tercer agente que oficia como administrador-operador y que garantiza los intercambios físicos y financieros, un despacho de energía centralizado y planificado en términos técnicos y económicos, y una oferta y demanda inelástica en el corto plazo $^{8}$.

\section{Metodología empleada (material y método)}

Son varios los modelos teóricos relacionados en la literatura microeconómica que tratan de representar de manera formal el comportamiento estratégico de agentes económicos que participan de escenarios oligopólicos. Uno de estos es el denominado

8 Quien asume estas responsabilidades en el interior del mercado de energía colombiano es XM.S.A E.S.P. 
"Modelo de equilibrio de Nash-Cournot" (Vega Redondo, 2000 y Millar, 1995).

Es importante resaltar que este modelo teórico ha sido la base de un sinnúmero de modelos de simulación de mercados imperfectos, empleados en diferentes tipos de análisis de regulación económica, poder de mercado y economía del bienestar aplicado. Como ejemplo, tenemos las metodologías desarrolladas en los trabajos de Alarcón (2002), García y Arbeláez (2002), García (2006), Campos (2005), Green (2004) y Rojas (2001).

\section{Modelo de simulación del mercado de energía eléctrica colombiano (MEC)}

El modelo de simulación del MEC lo conforma básicamente una oferta agregada de energía que se representa desde una función a trozos, constituida por los dos grupos de agentes generadores identificados: el grupo de generadores Oligopolio y el grupo de generadores competidores. Adicionalmente, se cuenta con la demanda de energía, considerada como inelástica en el corto plazo (García, 2006 y García y Arbeláez, 2002).

A continuación la descripción de cada uno de los grupos de oferentes y la forma en que son estimadas las cantidades de energía para generar, por cada uno de ellos:

\section{Oferta "Grupo Oligopolio"}

El Grupo Oligopolio lo conforman todas aquellas firmas que gozan de poder de mercado y que se comportan estratégicamente 9 . Su oferta de energía, de acuerdo con el marco teórico y el modelo de simulación, se estima a partir de un proceso de optimización restringida, a nivel de firma, en el que se maximiza una función objetivo (beneficios), decidiendo el nivel de generación de energía $q_{i, t}^{*}$ de la firma "i" en el instante " $t$ ", que a su vez depende de variables como el nivel de embalse en el periodo ( $\mathrm{t}$ ), el total de aportes hídricos a su sistema de embalse en el periodo ( $\mathrm{t}$ ) medidos en unidades de energía $(\mathrm{kWh})$ y el nivel de generación de las firmas $\operatorname{adversarias}^{10}$.

Esta función de beneficios (9) se compone del ingreso que percibe la firma "i”" por la venta de la energía generada en el instante " $t$ " en el mercado (spot) más el

9 Estas firmas son: EMGESA S.A con sus plantas Betania y Guavio; EPM S.P con sus plantas Playas, La Tasajera, Troneras y Guatapé; AES Chivor S.C.A con su planta Chivor; Electrificadora del Tolima con su planta Prado; Empresa URRA S.A con su planta Urra; EPSA S.P con sus plantas Salvajina y Calima, e Isagen E.S.P con sus plantas Miel I y Jaguas.

10 La estimación de los niveles $q_{i, t}^{*}$, se consigue a partir de un modelo de simulación programado en lenguaje Visual Basic y que recurre a la herramienta Solver, que permite resolver modelos de optimización restringida como el descrito en este aparte. Se alimenta el modelo de simulación con información histórica diaria entre 1997 y 2006 de aportes hídricos a embalses y nivel de embalses medidos en $\mathrm{kWh}$ y paramentos como capacidad mínima y máxima de embalse, capacidad de generación e ingresos correspondientes a contratos bilaterales suscritos (XM.S.A.E.S.P). 
ingreso percibido por la energía que se ha comprometido en contratos de generación bilaterales y que debe ser despachada en el instante " $t$ " a un precio predeterminado (García y Arbeláez, 2002).

$$
\prod_{i t}=P_{c, i, t} * q_{c, i, t}+\left(q_{i, t}^{*}-q_{c, i, l}\right) * P_{s p o t, t}
$$

Donde $\mathrm{P}_{c, i, t}=$ precio pactado por la firma (i) por unidad de energía en contratos bilaterales por despachar en el instante " $\mathrm{t}$ ".

$$
\begin{aligned}
q_{c, i, t,}= & \text { cantidad total de energía (kWh) pactada por la firma (i) en } \\
& \text { contratos bilaterales por despachar en el instante " } \mathrm{t} \text { ". } \\
P_{\text {spot, } t}= & \begin{array}{l}
\text { Precio de mercado de la energía en función de la cantidad total } \\
\text { de energía que genera el Grupo Oligopolio en el instante " } \mathrm{t} \text { ". }
\end{array}
\end{aligned}
$$

Por su parte, las restricciones asociadas al problema y que se deben cumplir una vez encontrada la solución óptima $q_{i, t}^{*}$ a partir del modelo de simulación, son las siguientes:

- En nivel del embalse de la firma (i), al final del último día del mes simulado, debe ser igual al nivel de embalse asociado el primer día del mes siguiente.

- $\quad$ El nivel del embalse de la firma (i), debe ser siempre menor o igual a la compacidad máxima de dicho embalse.

- En nivel del embalse de la firma (i), debe ser siempre mayor o igual al nivel mínimo de embalse establecido por el administrador del mercado.

- $\quad$ El volumen de vertimientos (agua que se libera del embalse y que no se utiliza en el proceso de generación de energía), debe ser mayor que cero.

- El nivel de generación de energía de la firma (i) debe ser menor o igual a su capacidad máxima de generación.

- El nivel de generación de la firma (i), debe ser siempre mayor o igual a cero.

Finalmente, la oferta total del Grupo Oligopolio se consigue agregando los niveles de generación óptima que se ha estimado para cada firma, como resultado del desarrollo del anterior proceso.

$$
Q_{\text {oligo }}=q_{1}^{*}+q_{2}^{*}+\ldots+q_{n}^{*}
$$




\section{Función oferta Grupo Competidor}

El segundo grupo de agentes generadores está integrado por todas aquellas firmas o plantas que hacen parte del sistema de generación nacional y que no gozan de poder de mercado. Dada esta condición, se asume que este grupo se comporta competitivamente, razón por la cual ofertan su capacidad de generación diaria (medida en $\mathrm{kWh}$ ) a precios que igualan su costo marginal.

Dada esta última condición, es posible representarlos desde una función inversa de oferta para cada mes del año, que se estima a partir de la información sobre ofertas diarias realizadas por el grupo, en términos de cantidad y precio, al administrador del mercado. Como ejemplo, a continuación se presenta la función inversa de oferta “Grupo Competidor” correspondiente al mes de enero del periodo 2005-2006".

$$
\begin{aligned}
& P_{\text {spot }}=-4.22 E^{+03}+2.96 E^{001} Q^{0.5}-6.06 E^{-04} Q+1.05 E^{11} Q^{2}-1.57 E^{-19} Q^{3}+1.57 E^{27} Q^{4} \\
& -8.44 E^{-36} Q^{5}+2.56 E^{-44} Q^{6}-3.21 E^{-53} Q^{7}
\end{aligned}
$$

En donde:

$$
\begin{aligned}
P_{\text {Spot }}= & \text { precio de mercado del bien energía } \\
Q \quad= & \text { Cantidad de energía }(\mathrm{kWh}) \text { generada/ofertada por el } \\
& \text { "Grupo Competidor". }
\end{aligned}
$$

11 Cada una de estas funciones se estiman a partir de información histórica de ofertas diarias entre 1998 y 2006 , tanto de precio por kWh como de $\mathrm{kWh}$, realizadas por 51 firmas/plantas de generación térmicas e hidráulicas que no hacen parte del Grupo Oligopolio, al administrador del mercado XM (Bases de datos XM.S.A.E.S.P.). 
Figura 2. Oferta de energía Grupo Competidor (promedio precio $\mathrm{kWh}$ mes de enero 2005-2006).

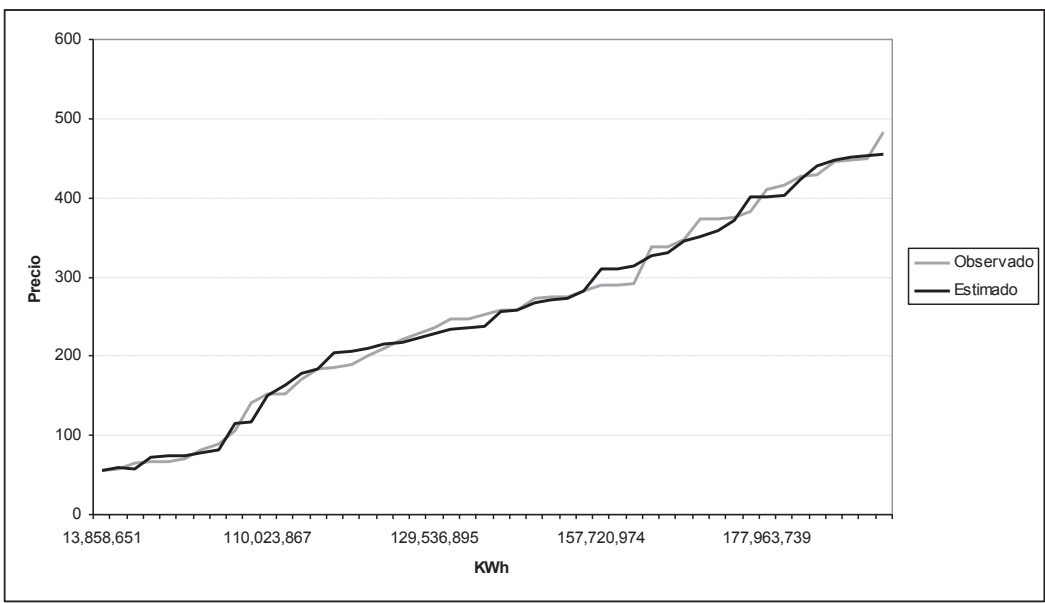

Fuente: XM S.A E.S.P. Cálculos propios.

Finalmente, la oferta total del mercado de energía eléctrica colombiano (MEC), se consigue agregando la generación correspondiente al "Grupo Oligopolio", junto a la generación del "Grupo Competidor", tal como se representa en la ecuación 11 y la Fig. $3^{12}$.

$$
Q_{\text {total }}=Q_{\text {oligo }}+Q_{\text {competidor }}
$$

12 La razón de la ubicación de la oferta agregada de energía del Grupo Oligopolio, sobre el eje "X”, se explica dado el supuesto de costos y costo marginal igual a cero para este grupo. 
Figura 3.

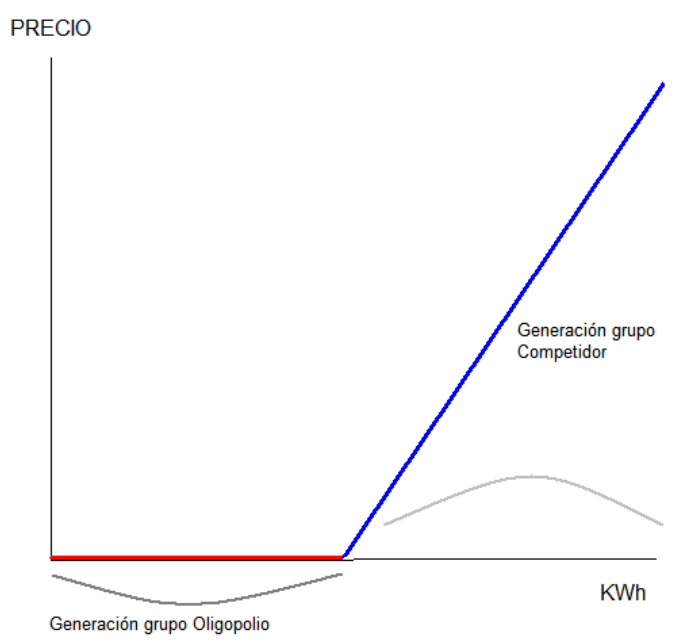

Fuente: autor.

Una vez identificada la oferta de energía y conocida la demanda, se procede a recrear de manera simplificada el mercado de energía tal como se presenta en la figura 4. En esta figura la recta rojo-azul simboliza la oferta total de energía, mientras que la recta vertical (gris) corresponde a la demanda de energía que se definió como inelástica en el corto plazo.

Figura 4.

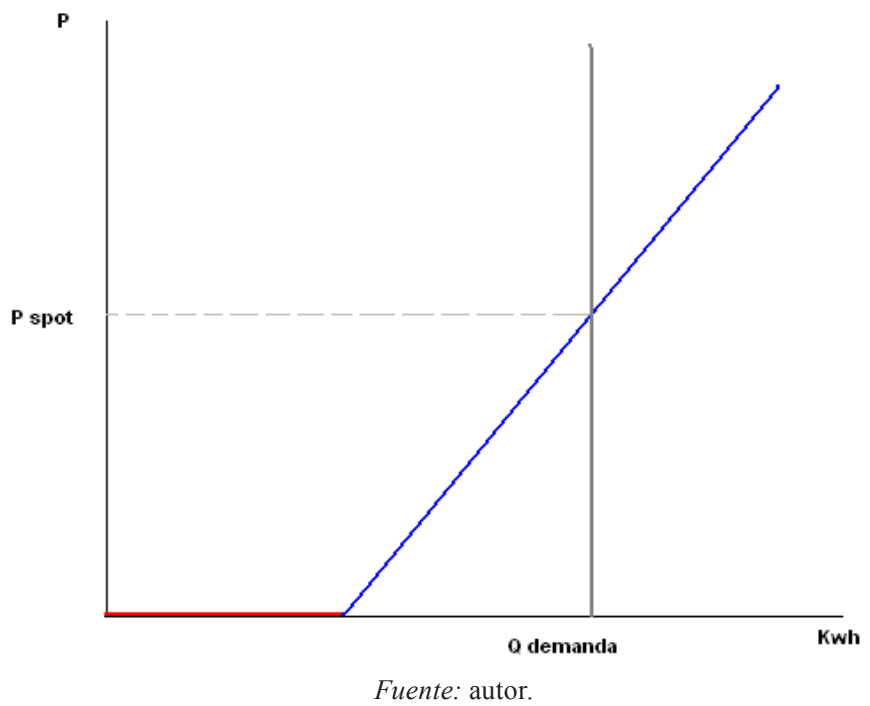


Por su parte, el precio de mercado (spot) de la energía será aquel que consigue el cumplimiento de la condición de equilibrio (12), además de ser igual al valor ofertado por el último generador competidor que fue despachado y que garantizó el que se atendiera a la totalidad de la demanda.

$$
Q_{0}=Q_{d}
$$

Como se mencionó anteriormente, las firmas que operan tecnologías hidráulicas y que además cuentan con embalses de regulación conforman un oligopolio que decide estratégicamente la cantidad de energía para ofertar, en pro de la consecución del máximo beneficio y en función de los niveles de embalse y aportes hídricos que reporten. Indirectamente cada decisión de generación agregada de este grupo determinará el precio de mercado (spot) de la manera como se representa en el figura 5.

Figura 5.

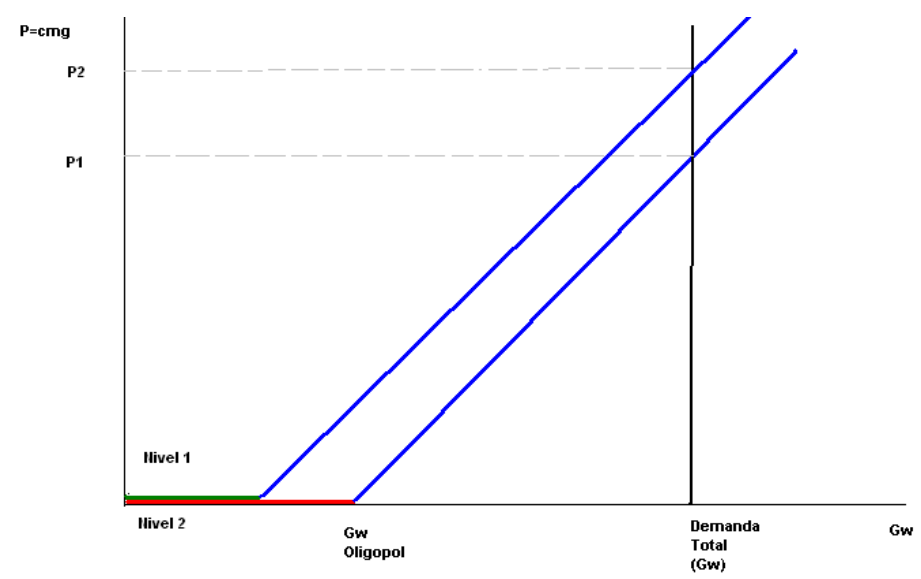

Fuente: autor.

En el primero de los casos (recta verde-escenario hidrología NIÑO), la generación óptima total agregada de las empresas oligopólicas es inferior a la representada por la segunda recta (roja-escenario hidrología normal). Esta menor oferta oligopólica que podría deberse a reducciones efectivas o esperadas en los aportes hídricos que alimentan el sistema de embalse, como consecuencia de la ocurrencia de fenómenos climatológicos extremos desencadenados por la intensificación del proceso de calentamiento global o El Niño (ENOS), es responsable de un mayor precio de mercado (spot) de la energía y de pérdidas de bienestar de los consumidores, que se 
aproxima a partir de la variación (delta) en el excedente del productor entre estos dos escenarios, dada la inelasticidad de la demanda de energía.

Finalmente, el modelo de simulación computacional del mercado se construye tomando como base el anterior esquema.

\section{Resultados}

A continuación los resultados obtenidos del ejercicio de simulación del mercado de energía colombiano (MEC) y de la estimación del cambio en las medidas de bienestar de los agentes económicos que participan de este, como consecuencia de la ocurrencia del fenómeno El Niño (ENOS) y su intensificación, debido probablemente a la acentuación del proceso de "calentamiento global-cambio climático". Antes de entrar a los resultados se presenta un breve análisis de ajuste del modelo de simulación.

\section{Análisis ajuste del modelo}

El modelo de simulación del (MEC) empleado, reporta el siguiente nivel de ajuste: $-6 \%$ de error promedio en la estimación del precio kilovatio hora $(\mathrm{kWh})$ mensual para el año 1997 y un $2 \%$ de error en la estimación del precio del kWh mensual para el año 1998. Así mismo, reporta un error del 6\% en la estimación del precio promedio mensual del kWh de energía transado en el 2005 y del 7\% para el kWh transado en el $2006^{13}$.

Se recuerda que las simulaciones se realizaron para los periodos 1997-1998 y 2005 2006, por lo que fueron utilizadas funciones "grupo competidor-mes" diferenciadas por periodo de análisis.

13 Se aclara que el ejercicio de análisis de ajuste del modelo se efectuó simulando primero el comportamiento del mercado bajo condiciones de demanda, contratación e hidrología reportadas en estos dos periodos (marzo de 1997 a mayo de 1998) y (septiembre del 2005 y agosto del 2006) y contrastando los resultados obtenidos (precio) frente a los valores reales observados por esta variable a lo largo de este mismo periodo de tiempo. 
Impacto sobre el bienestar social atribuido al fenomeno El niño (ENOS) y al proceso ...

Tabla 3. Ajuste modelo de simulación eventos El Niño (ENOS) 1997-1998 y normal 2005-2006. Precio Kw/ hora (\$/kwh)

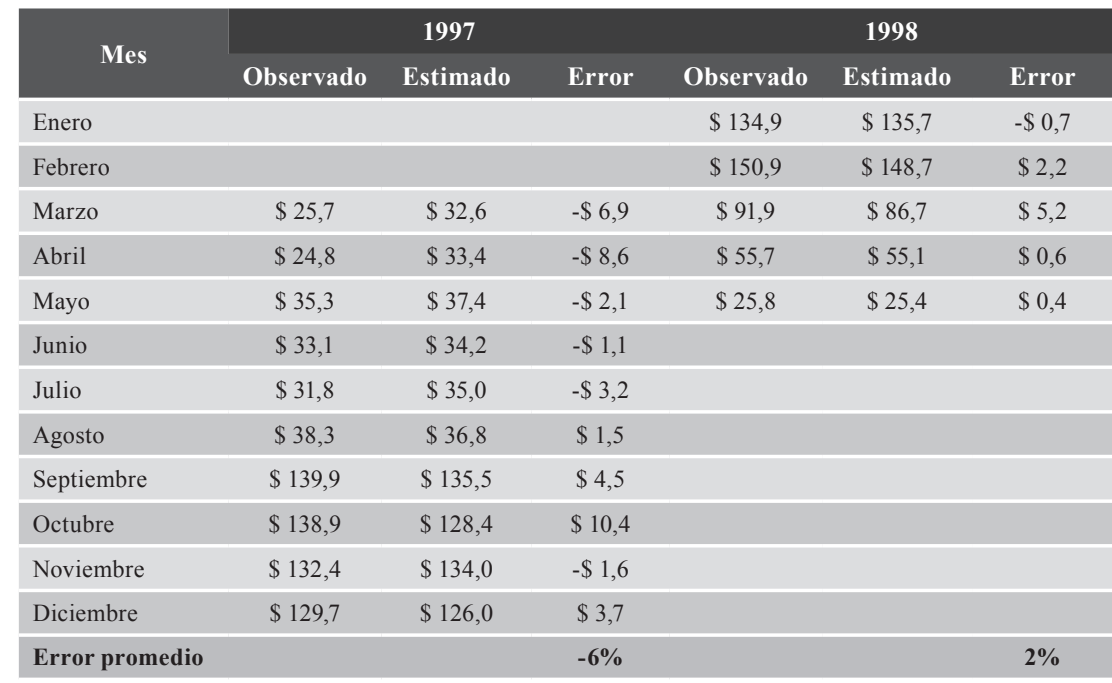

\begin{tabular}{|l|c|c|c|c|c|c|}
\hline \multirow{2}{*}{ Mes } & \multicolumn{3}{|c|}{$\mathbf{2 0 0 5}$} & & \multicolumn{3}{c|}{$\mathbf{2 0 0 6}$} \\
\cline { 2 - 6 } & Observado & Estimado & Error & Observado & Estimado & Error \\
\hline Enero & & & $\$ 79,4$ & $\$ 74,6$ & $\$ 4,8$ \\
\hline Febrero & & & $\$ 75,7$ & $\$ 73,5$ & $\$ 2,2$ \\
\hline Marzo & & $\$ 66,2$ & $\$ 64,8$ & $\$ 1,4$ \\
\hline Abril & & & $\$ 54,7$ & $\$ 53,5$ & $\$ 1,2$ \\
\hline Mayo & & $\$ 54,4$ & $\$ 59,0$ & $-\$ 4,6$ \\
\hline Junio & & & $\$ 53,6$ & $\$ 58,9$ & $-\$ 5,3$ \\
\hline Julio & & $\$ 59,0$ & $\$ 68,8$ & $-\$ 9,8$ \\
\hline Agosto & & & $\$ 66,9$ & $\$ 61,3$ & $\$ 5,6$ \\
\hline Septiembre & $\$ 87,8$ & $\$ 86,0$ & $\$ 1,8$ & & & \\
\hline Octubre & $\$ 81,5$ & $\$ 79,7$ & $\$ 1,8$ & & & \\
\hline Noviembre & $\$ 57,0$ & $\$ 50,2$ & $\$ 6,8$ & & & \\
\hline Diciembre & $\$ 80,5$ & $\$ 75,0$ & $\$ 5,5$ & & & $\mathbf{7 \%}$ \\
\hline Error promedio & & & $\mathbf{6 \%}$ & & \\
\hline
\end{tabular}

Fuente: autor. 


\section{Estimación de impactos sobre el sector generador y el bienestar de los consumidores. Evento EI Niño (ENOS) 1997-1998}

Los impactos asociados a la ocurrencia del fenómeno El Niño (ENOS) se deben, según lo expuesto en apartes anteriores, a reducciones en los aportes y rendimientos hídricos de los afluentes que alimentan el sistema de embalse del Grupo Oligopolio. Se aclara que dichas reducciones como el impacto resultado de estas, varían entre meses y años de ocurrencia del evento.

En este sentido, para el evento del periodo 1997-1998, y a lo largo del primer año de ocurrencia (1997), las reducciones en los rendimientos de los afluentes que alimentan el sistema de embalse del Grupo Oligopolio alcanzaron el 14\%, mientras que para el segundo año (1998) dichas reducciones fueron tan solo del $9 \%{ }^{14}$. Sin embargo, al calcularlas únicamente entre los meses en que se reporta el fenómeno (marzo 1997 a mayo 1998), estas ascienden al 27\%, siendo el año 1998 el de mayor nivel de disminución de aportes con un $38 \%$.

Por meses, las mayores reducciones se registraron al final de la segunda estación seca del primer año (septiembre) con un 49\%, como en los correspondientes a la segunda estación lluviosa de ese año (meses de octubre noviembre) con reducciones del $57 \%$. Este comportamiento se extiende hasta los meses que hacen parte de la primera estación seca del 1998 (diciembre, enero, febrero y marzo) con reducciones promedio del $52 \%$.

Tabla 4. Variación rendimientos hídricos afluentes / Precios energía promedio mes Observado-estimado (\$/kwh). Evento El Niño (ENOS) 1997-1998

\begin{tabular}{|c|c|c|c|c|c|c|}
\hline \multirow{3}{*}{ MES } & \multicolumn{2}{|c|}{$\begin{array}{l}\text { Variación Rendimientos } \\
\text { Hídricos Afluentes Sistema (\%) }\end{array}$} & \multicolumn{4}{|c|}{$\begin{array}{l}\text { Precios KWh energía } \\
\text { promedio mes }\end{array}$} \\
\hline & \multirow{2}{*}{1997} & \multirow{2}{*}{1998} & \multicolumn{2}{|c|}{1997} & \multicolumn{2}{|c|}{1998} \\
\hline & & & Observado & Estimado & Observado & Estimado \\
\hline Enero & $18 \%$ & $-61 \%$ & & & $\$ 134,9$ & $\$ 135,7$ \\
\hline Febrero & $23 \%$ & $-50 \%$ & & & $\$ 150,9$ & $\$ 148,7$ \\
\hline Marzo & $-4 \%$ & $-41 \%$ & $\$ 25,7$ & $\$ 32,6$ & $\$ 91,9$ & $\$ 86,7$ \\
\hline Abril & $-19 \%$ & $-29 \%$ & $\$ 24,8$ & $\$ 33,4$ & $\$ 55,7$ & $\$ 55,1$ \\
\hline Mayo & $-18 \%$ & $-8 \%$ & $\$ 35,3$ & $\$ 37,4$ & $\$ 25,8$ & $\$ 25,4$ \\
\hline Junio & $-15 \%$ & $26 \%$ & $\$ 33,1$ & $\$ 34,2$ & & \\
\hline Julio & $73 \%$ & $76 \%$ & $\$ 31,8$ & $\$ 35,0$ & & \\
\hline
\end{tabular}

14 Estas reducciones se estiman tomando como base el total de los aportes hídricos promedio del escenario normal series históricas 2001-2003-2005 (XM S.A E.S.P.). 


\begin{tabular}{|c|c|c|c|c|c|c|}
\hline Agosto & $-10 \%$ & $0 \%$ & $\$ 38,3$ & $\$ 36,8$ & & \\
\hline Septiembre & $-49 \%$ & $-17 \%$ & $\$ 139,9$ & $\$ 135,5$ & & \\
\hline Octubre & $-57 \%$ & $-17 \%$ & $\$ 138,9$ & $\$ 128,4$ & & \\
\hline Noviembre & $-57 \%$ & $-29 \%$ & $\$ 132,4$ & $\$ 134,0$ & & \\
\hline Diciembre & $-55 \%$ & $35 \%$ & $\$ 129,7$ & $\$ 126,0$ & & \\
\hline $\begin{array}{l}\text { Total / } \\
\text { Promedio }\end{array}$ & $-14 \%$ & $-9 \%$ & $\$ 73,0$ & $\$ 73,3$ & $\$ 57,8$ & $\$ 55,7$ \\
\hline
\end{tabular}

Fuente: XM. S.A.E.S.P. Cálculos del autor.

Como resultado de la disminución de los rendimientos y aportes hídricos de los afluentes que alimentan el sistema de embalse del Grupo Oligopolio, a lo largo del evento El Niño (ENOS) 1997-1998, el modelo de simulación estima un aumento del $45 \%$ en la participación del grupo "Competidor" dentro de la generación total de energía. De otro lado, el "Grupo Oligopolio" (integrado por las mayores plantas de generación hidráulica) registra una reducción en su oferta de energía del 30\%.

Esta reconfiguración de la composición de la oferta total de energía a lo largo del evento bajo análisis, explicaría el aumento del precio del $\mathrm{kWh}$ de energía transada en dicho mercado, el cual fue del $271 \%$ entre la primera y la segunda estación lluviosa del año 1997.

Tabla 5. Generación estimada grupos “Competidor” y "Oligopolio” Evento El Niño (ENOS) 1997-1998 y normal

\begin{tabular}{|c|c|c|c|c|c|c|c|c|}
\hline \multirow[t]{2}{*}{ AÑ̃o } & \multirow[t]{2}{*}{ MES } & \multicolumn{2}{|c|}{ Evento Niño (Estimado) [1] } & \multicolumn{2}{|c|}{ Evento Normal (Estimado) [2] } & \multicolumn{2}{|c|}{$\begin{array}{c}\text { Variación Participación } \\
\text { por Grupos de } \\
\text { Generadores }\end{array}$} & \multirow{2}{*}{$\begin{array}{c}\text { Variación } \\
\text { Rendimientos } \\
\text { Hídricos } \\
\text { Afluentes } \\
\text { Sistema (\%) }\end{array}$} \\
\hline & & Competidor & Oligopolio & Competidor & Oligopolio & Competidor & Oligopolio & \\
\hline 1997 & Marzo & $262.811 .302,43$ & $3.182 .086 .657,57$ & $1.463 .316 .725,10$ & 1.981.581.234,90 & $-82 \%$ & $61 \%$ & $-4 \%$ \\
\hline 1997 & Abril & $703.363 .049,12$ & $2.750 .667 .870,88$ & $1.652 .388 .163,36$ & $1.801 .642 .756,64$ & $-57 \%$ & $53 \%$ & $-19 \%$ \\
\hline 1997 & Mayo & $2.516 .325 .648,60$ & 1.074.316.771,40 & $1.448 .421 .120,71$ & 2.142.221.299,29 & $74 \%$ & $-50 \%$ & $-18 \%$ \\
\hline 1997 & Junio & $2.440 .334 .288,43$ & $944.595 .211,57$ & $1.002 .560 .884,60$ & 2.382.368.615,40 & $143 \%$ & $-60 \%$ & $-15 \%$ \\
\hline 1997 & Julio & $2.182 .033 .210,17$ & $1.400 .350 .729,83$ & $1.300 .457 .982,39$ & 2.281.925.957,61 & $68 \%$ & $-39 \%$ & $73 \%$ \\
\hline 1997 & Agosto & 2.344.550.521,75 & $1.260 .649 .968,25$ & $1.340 .088 .106,86$ & $2.265 .112 .383,14$ & $75 \%$ & $-44 \%$ & $-10 \%$ \\
\hline 1997 & Septiembre & 2.234.423.799,09 & $1.243 .895 .640,91$ & $1.506 .038 .993,99$ & $1.972 .280 .446,01$ & $48 \%$ & $-37 \%$ & $-49 \%$ \\
\hline 1997 & Octubre & 2.569.585.981,92 & $1.084 .627 .568,08$ & $1.507 .985 .088,10$ & $2.146 .228 .461,90$ & $70 \%$ & $-49 \%$ & $-57 \%$ \\
\hline 1997 & Noviembre & 2.623.247.136,30 & $887.205 .533,70$ & $1.583 .084 .884,55$ & $1.927 .367 .785,45$ & $66 \%$ & $-54 \%$ & $-57 \%$ \\
\hline 1997 & Diciembre & $2.764 .814 .344,50$ & $797.962 .605,50$ & $1.675 .067 .519,11$ & $1.887 .709 .430,89$ & $65 \%$ & $-58 \%$ & $-55 \%$ \\
\hline 1998 & Enero & $1.713 .895 .149,95$ & $1.916 .377 .200,05$ & 1.217.286.248,48 & $2.415 .845 .747,50$ & $41 \%$ & $-21 \%$ & $-61 \%$ \\
\hline 1998 & Febrero & $1.593 .335 .811,14$ & $1.720 .408 .308,86$ & $1.005 .639 .934,22$ & $2.308 .104 .185,78$ & $58 \%$ & $-25 \%$ & $-50 \%$ \\
\hline 1998 & Marzo & $2.423 .333 .448,17$ & $1.259 .841 .371,83$ & $1.241 .352 .435,05$ & $2.441 .822 .384,95$ & $95 \%$ & $-48 \%$ & $-41 \%$ \\
\hline 1998 & Abril & $2.620 .470 .723,70$ & $963.647 .416,30$ & $1.782 .475 .383,36$ & $1.801 .642 .756,64$ & $47 \%$ & $-47 \%$ & $-29 \%$ \\
\hline 1998 & Mayo & $1.849 .403 .796,76$ & $1.805 .565 .323,24$ & $1.512 .747 .820,71$ & 2.142.221.299,29 & $22 \%$ & $-16 \%$ & $-8 \%$ \\
\hline Total & Promedio & $30.841 .928 .212,03$ & $22.292 .198 .177,97$ & $21.238 .911 .290,61$ & $31.898 .074 .745,38$ & $45 \%$ & $-30 \%$ & $-27 \%$ \\
\hline
\end{tabular}

[1] Estimaciones con base aportes hídricos por afluente (Kwh) observados años 1997-1998.

[2] Estimaciones con base aportes hídricos por afluente (k.o.) observados año 2005 (mejor año hidrología normal)

Fuente: autor. 
En este sentido, el impacto sobre el bienestar de los consumidores que participan del mercado de energía colombiano (MEC), como resultado de la ocurrencia del evento El Niño (ENOS) del periodo 1997-1998, se estima a partir del cálculo del cambio observado en el excedente del productor entre escenarios de hidrología base o normal y Niño (ENOS) ${ }^{15}$.

Tabla 6. Impactos sobre el bienestar de los consumidores, evento El Niño (ENOS) 1997-1998 (Millones de pesos corrientes de 1998)

\begin{tabular}{|c|c|c|c|c|c|}
\hline \multirow{2}{*}{ Año } & \multirow{2}{*}{ Mes } & \multicolumn{3}{|c|}{ Excedente del productor } & \multirow{2}{*}{$\begin{array}{c}\text { Variación } \\
\text { Rendimientos } \\
\text { Hidricos Afluentes } \\
\text { Sistema (\%) }\end{array}$} \\
\hline & & Niño & Normal & "Variación & \\
\hline 1997 & Mayo & $\$ 75.986$ & $\$ 58.040$ & $\$ 17.946$ & $-18 \%$ \\
\hline 1997 & Junio & $\$ 68.651$ & $\$ 49.003$ & $\$ 19.649$ & $-15 \%$ \\
\hline 1997 & Julio & \$ 91.191 & $\$ 51.425$ & $\$ 39.767$ & $73 \%$ \\
\hline 1997 & Agosto & $\$ 88.330$ & $\$ 62.425$ & $\$ 25.905$ & $-10 \%$ \\
\hline 1997 & Septiembre & $\$ 348.504$ & $\$ 206.191$ & $\$ 142.313$ & $-49 \%$ \\
\hline 1997 & Octubre & $\$ 353.840$ & $\$ 170.402$ & $\$ 183.439$ & $-57 \%$ \\
\hline 1997 & Noviembre & $\$ 342.159$ & $\$ 157.674$ & $\$ 184.485$ & $-57 \%$ \\
\hline 1997 & Diciembre & $\$ 312.183$ & $\$ 154.300$ & $\$ 157.883$ & $-55 \%$ \\
\hline 1998 & Enero & $\$ 406.606$ & $\$ 195.896$ & $\$ 210.710$ & $-61 \%$ \\
\hline 1998 & Febrero & \$ 395.922 & $\$ 160.003$ & $\$ 235.919$ & $-50 \%$ \\
\hline 1998 & Marzo & $\$ 175.400$ & $\$ 153.771$ & $\$ 21.629$ & $-41 \%$ \\
\hline \multicolumn{4}{|c|}{ CAMBIO EXCEDENTE } & \$1.239.644 & $-27 \%$ \\
\hline
\end{tabular}

Fuente: autor.

Finalmente, el ejercicio permitió establecer que el evento El Niño (ENOS) registrado en el periodo 1997-1998 ocasionó pérdidas del bienestar de los consumidores, valoradas en $\$ 1,2$ billones, equivalentes al $0.9 \%$ del PIB en pesos corrientes del 1998. Esta cifra daría cuenta de la máxima disponibilidad por pagar (DAP) de los agentes perdedores que participan del mercado de energía, por la adopción de cualquier política que minimice el impacto y los riesgos asociados con la ocurrencia de este tipo de eventos climáticos.

15 La simulación del comportamiento del mercado ante escenarios de hidrología normal se efectúa manteniendo los registros de las demás variables de control observados en el periodo de simulación (1997-1998). Estas variables son la demanda observada y los niveles de contratación de cada firma partícipe. 


\section{Estimación de impactos sobre el sector generador y el bienestar de los consumidores. Simulación intensificación fenómeno El Niño (ENOS)}

A continuación, los resultados del ejercicio de estimación del impacto sobre el bienestar de los consumidores que participan del mercado de energía colombiano (MEC), como consecuencia del aumento en la intensidad del fenómeno El Niño (ENOS), posiblemente debido a la acentuación del proceso de "cambio climático" o "calentamiento global".

La simulación del comportamiento del (MEC) se efectúa tomando seis posibles escenarios que representan igual número de niveles de intensidad del fenómeno El Niño (ENOS)" junto a la demanda y los niveles de contratación de las firmas generadoras oligopólicas, observados entre el mes de septiembre de 2005 y agosto de 2006. De igual forma, se simuló el comportamiento del mercado bajo condiciones de hidrología normal. Los resultados de esta simulación fueron utilizados como línea base dentro del análisis.

En primera medida, se encontró que como consecuencia de la reducción en los rendimientos de los afluentes por efecto de la ocurrencia de un evento El Niño (ENOS) de intensidad promedio (19\% de reducción aportes hídricos año corrido), la generación del Grupo Oligopolio se reduce en un $22 \%$, en relación con la generación que causaría el grupo de experimentar un escenario "base" o de hidrología normal.

Tabla 7. Generación estimada escenario base y reducciones de generación por escenario "intensidades El Niño", grupo Oligopolio

\begin{tabular}{|c|c|c|c|c|c|c|c|}
\hline Mes & Base & $\begin{array}{c}\text { Niño } \\
\text { Promedio }\end{array}$ & $\begin{array}{c}\text { Escenario } \\
1\end{array}$ & $\begin{array}{c}\text { Escenario } \\
2\end{array}$ & $\begin{array}{c}\text { Escenario } \\
3\end{array}$ & $\begin{array}{c}\text { Escenario } \\
4\end{array}$ & $\begin{array}{c}\text { Escenario } \\
5\end{array}$ \\
\hline Enero & 1.901 .141 .665 & $-3 \%$ & $-6 \%$ & $-7 \%$ & $-9 \%$ & $-11 \%$ & $-13 \%$ \\
\hline Febrero & 1.750 .575 .408 & $-30 \%$ & $-34 \%$ & $-36 \%$ & $-38 \%$ & $-41 \%$ & $-43 \%$ \\
\hline Marzo & 2.052 .526 .823 & $-19 \%$ & $-24 \%$ & $-28 \%$ & $-31 \%$ & $-35 \%$ & $-38 \%$ \\
\hline Abril & 1.881 .479 .344 & $-20 \%$ & $-26 \%$ & $-32 \%$ & $-37 \%$ & $-43 \%$ & $-48 \%$ \\
\hline Mayo & 2.283 .659 .330 & $-19 \%$ & $-25 \%$ & $-30 \%$ & $-35 \%$ & $-42 \%$ & $-48 \%$ \\
\hline Junio & 2.538 .799 .642 & $-36 \%$ & $-39 \%$ & $-44 \%$ & $-49 \%$ & $-54 \%$ & $-59 \%$ \\
\hline Julio & 2.434 .971 .874 & $0 \%$ & $-7 \%$ & $-12 \%$ & $-18 \%$ & $-24 \%$ & $-29 \%$ \\
\hline Agosto & 2.405 .172 .086 & $-16 \%$ & $-19 \%$ & $-24 \%$ & $-30 \%$ & $-35 \%$ & $-41 \%$ \\
\hline Septiembre & 2.090 .809 .129 & $-30 \%$ & $-37 \%$ & $-42 \%$ & $-48 \%$ & $-53 \%$ & $-57 \%$ \\
\hline Octubre & 2.286 .034 .510 & $-36 \%$ & $-44 \%$ & $-50 \%$ & $-56 \%$ & $-62 \%$ & $-67 \%$ \\
\hline
\end{tabular}




\begin{tabular}{|c|c|c|c|c|c|c|c|}
\hline Noviembre & 2.069 .251 .677 & $-37 \%$ & $-46 \%$ & $-51 \%$ & $-57 \%$ & $-63 \%$ & $-68 \%$ \\
\hline Diciembre & 1.993.112.179 & $-18 \%$ & $-22 \%$ & $-25 \%$ & $-28 \%$ & $-31 \%$ & $-33 \%$ \\
\hline $\begin{array}{l}\text { "Total General / } \\
\text { Promedio Año" }\end{array}$ & 25.687 .533 .668 & $-22 \%$ & $-27 \%$ & $-32 \%$ & $-37 \%$ & $-41 \%$ & $-46 \%$ \\
\hline \multicolumn{2}{|c|}{$\begin{array}{l}\text { Porcentaje de Reducción } \\
\text { Aportes Hídricos por año }\end{array}$} & $-19 \%$ & $-30 \%$ & $-35 \%$ & $-40 \%$ & $-45 \%$ & $-50 \%$ \\
\hline
\end{tabular}

Fuente: autor.

Por su parte, si el evento genera reducciones del 30\% (promedio anual) en la disponibilidad hídrica, el Grupo Oligopolio reduciría su generación en un 27\%. Ante la ocurrencia de eventos de fuerte intensidad que propicie reducciones en los rendimientos de los afluentes superiores al 40\% y hasta un 50\% (promedio anual), la generación del grupo se reduciría hasta en un $45 \%$. Todas estas reducciones en la generación del "Grupo Oligopolio" son asumidas por el "Grupo Competidor".

En cuanto al impacto sobre el bienestar debido al aumento en la intensidad del evento El Niño (ENOS), las simulaciones permitieron establecer impactos anuales valorados en $\$ 907$ mil millones (corrientes de 2006), como consecuencia de la ocurrencia de eventos EL Niño (ENOS) de intensidad promedio (reducciones en los aportes hídricos del 19\% promedio anual). Este impacto equivaldría al $0.24 \%$ del PIB o al 12\% del PIB del sector energía eléctrica correspondiente al 2006.

Tabla 8. Impactos sobre el bienestar de los consumidores, escenarios El Niño (ENOS) y grados de intensidad (Millones de pesos corrientes de 2006

\begin{tabular}{|c|c|c|c|c|c|}
\hline Escenario & $\begin{array}{c}\text { Excedente } \\
\text { productores }\end{array}$ & $\begin{array}{c}\text { Impacto sobre } \\
\text { el bienestar } \\
\text { Consumidores }\end{array}$ & $\begin{array}{c}\text { \% Reducción } \\
\text { Aportes } \\
\text { Hídricos }\end{array}$ & $\begin{array}{c}\text { \% Impacto sobre } \\
\text { el Bienestar PIB } \\
2006\end{array}$ & $\begin{array}{c}\% \text { PIB sector } \\
2006\end{array}$ \\
\hline NORMAL (base) & $\$ 2.902 .810$ & & & & \\
\hline NIÑO (promedio) & $\$ 3.809 .963$ & $\$ 907.154$ & $19 \%$ & $0,24 \%$ & $12 \%$ \\
\hline NIÑO Escenario 1 & $\$ 4.267 .494$ & $\$ 1.364 .684$ & $30 \%$ & $0,36 \%$ & $17 \%$ \\
\hline NIÑO Escenario 2 & $\$ 4.645 .015$ & $\$ 1.742 .205$ & $35 \%$ & $0,46 \%$ & $22 \%$ \\
\hline NIÑO Escenario 3 & $\$ 5.048 .566$ & $\$ 2.145 .756$ & $40 \%$ & $0,57 \%$ & $27 \%$ \\
\hline NIÑO Escenario 4 & $\$ 5.480 .570$ & $\$ 2.577 .760$ & $45 \%$ & $0,68 \%$ & $33 \%$ \\
\hline NIÑO Escenario 5 & $\$ 5.908 .557$ & $\$ 3.005 .747$ & $50 \%$ & $0,80 \%$ & $38 \%$ \\
\hline
\end{tabular}

Fuente: autor.

Por su parte, de reportarse eventos de mayor intensidad que ocasionen reducciones de los aportes hídricos en un rango entre el 35\% y el 50\% promedio anual, la disminución del bienestar de los consumidores se ubicaría anualmente entre los $\$ 2,1$ billones a los $\$ 3$ billones, equivalentes al $0.57 \%$ y el $0.8 \%$ del PIB del 2006 o al $27 \%$ y $38 \%$ del PIB del sector energía eléctrica correspondiente a este mismo año. 
Los resultados señalan que al aumentarse la intensidad del fenómeno, son mayores los impactos sobre el bienestar de los agentes que participan del mercado de energía. Dicha relación justifica el diseño y la implementación de políticas de adaptación a impactos y riesgos asociados a la ocurrencia e intensificación de este fenómeno climatológico, que acompañen a las que pretenden reducir la emisión de GEI.

\section{Conclusiones y recomendaciones}

Se estimó el impacto sobre el bienestar de los consumidores que participan del mercado de energía colombiano (MEC), como resultado de la ocurrencia e intensificación del fenómeno El Niño Oscilación del Sur (ENOS). Sin embargo, no se encontraron estudios que precisen o cuantifiquen el cambio marginal en el grado de intensificación, debido a aumentos en variables relacionadas con el proceso de calentamiento global como el nivel de concentración de gases efecto invernadero (GEI) o la temperatura media del planeta. Esto impidió que pudiera descomponerse el impacto sobre el bienestar entre responsables, como lo son la ocurrencia del evento en sí y el aumento en su intensidad debido al proceso de calentamiento global o cambio climático.

El ejercicio de estimación recurrió al empleo de un modelo de simulación computacional del mercado de energía colombiano (MEC), diseñado a partir del modelo de competencia oligopólica de Nash-Cournot.

Los resultados obtenidos señalan que los niveles de utilidad asociados a escenarios en los que no se reporta la ocurrencia del fenómeno El Niño (ENOS), son mayores que aquellos en los que sí se reporta su ocurrencia. Luego, la diferencia entre estos niveles o cambio en el bienestar estimado se entiende como la disponibilidad a pagar (DAP) de los agentes afectados, para evitar los efectos asociados con la ocurrencia o intensificación del fenómeno.

En cuanto a hallazgos, las simulaciones permitieron establecer que el evento El Niño (ENOS) registrado en el periodo 1997-1998 ocasionó una disminución del bienestar de los consumidores por valor de $\$ 1,2$ billones de pesos del año 98, equivalentes al $0.9 \%$ del PIB del este mismo año. Adicionalmente, se pudo estimar que la ocurrencia de eventos EL Niño (ENOS) de intensidad promedio (reducciones en aportes hídricos del 19\% promedio anual) generaría pérdidas en el bienestar de los consumidores por valor de $\$ 907$ mil millones (corrientes 2006) al año, equivalentes al $0.24 \%$ del PIB 2006 o al 12\% del PIB del sector de energía calculado para este mismo año.

De igual forma, de aumentarse la intensidad del fenómeno, debido posiblemente a la acentuación del proceso de cambio climático o calentamiento global, el impacto sobre el bienestar podría ascender al $0.8 \%$ del PIB nacional ( $\$ 3$ billones del año 2006). Esto de ocurrir eventos que propicien reducciones de la oferta hídrica del $50 \%$ promedio anual. 
En el caso de eventos que generen reducciones en la oferta hídrica en un rango entre el $30 \%$ y el $40 \%$ promedio anual, se estima que se causarían impactos sobre el bienestar de los consumidores entre los $\$ 1.3$ billones y los $\$ 2.1$ billones del 2006, equivalentes al $0.36 \%$ y el $0.57 \%$ del Producto Interno Bruto Nacional del 2006.

Estos resultados señalarían el alto impacto sobre el bienestar de la sociedad colombiana, debido a la ocurrencia e intensificación de este tipo de eventos. En tal sentido, los resultados aquí presentados deberán ser considerados al momento del diseño y evaluación de políticas de adaptación a los riesgos relacionados a este tipo de fenómenos, de mitigación de emisiones de gases efecto invernadero (GEI) a nivel nacional, o al instante de la ratificación o formulación de acuerdos internacionales sobre la materia.

Finalmente, se recomienda adelantar estudios que profundicen en la relación entre el proceso de calentamiento global o cambio climático y el fenómeno El Niño (ENOS), con los que se podría descomponer el impacto debido a cada uno de estos dos fenómenos climatológicos. Adicionalmente, se recomienda adelantar estudios de valoración económica sobre otros sectores de la economía sensibles a este tipo de eventos climatológicos, como para escenarios en los que se contemplen esquemas de regulación ambiental basados en tasas de uso de recursos naturales. Dichos estudios preferiblemente deberán apoyarse en metodologías de preferencias reveladas, en donde se estimen medidas exactas de bienestar (hicksianas), en lugar de medidas marshallianas como las presentadas en el actual trabajo. Se recomienda también adelantar estudios de valoración basados en modelos de equilibrio general.

\section{Referencias}

Alarcón, L. F. (2002). Metodología para el cálculo de requerimientos de eficiencia en integraciones económicas horizontales. Revista Desarrollo y Sociedad, $N^{o} .50$. Universidad de los Andes. Bogotá.

Bonilla, J. et al. (2003). El valor económico de la predicción del fenómeno El Niño Oscilación del Sur (ENOS) para el sector azucarero colombiano. Documento CEDE. Bogotá.

Campos Fernández, A. (2005). Modelo posibilista del mercado de energía eléctrica a mediano plazo en un entorno liberalizado. Universidad Pontificia Comillas de Madrid. Madrid.

Contraloría General de la República, ACOLGEN (2003). Taller sobre el sector eléctrico colombiano. Bogotá.

Corporación Andina de Fomento - CAF. (2002). El Niño, returns to the Andes. El Niño project. Washington, D.C. 
Deschenes, O. y Greenstone, M. (2007). Climate change, mortality, and adaptation: Evidence from annual fluctuations in weather in the US. MIT.

Deschenes, O. y Greenstone, M. (2004). The economic impacts of climate change: evidence from agricultural profits and random fluctuations in weather. MIT.

Eichberger, J. (1993). Game theory for economists. New York: Academic Press, INC.

García, A. (2006). Modeling electricity markets: A brief introduction. University of Virginia.

García, A. y Arbeláez, L. (2002). Market power analysis for the Colombian electricity market. Energy Economics, $N .^{\circ} 24$.

Green, R. (2004). Did english generators play cournot? Capacity with holding in the electricity pool. Center for Energy and Environmental Policy Research.

Ideam. (2006). El Niño en Colombia. Bogotá.

Ideam. (2002). Efectos naturales y socioeconómicos del fenómeno de El Niño en Colombia. Bogotá.

Iimi, A. (2007). Estimating global climate change impacts on hydropower projects. The World Bank.

IPCC (2007). Climate change 2007. IPCC Fourth Assessment Report (AR4). New York.

Medina, P. y Uribe, E. (2005). Evolución del servicio de energía eléctrica durante la última década. Documento CEDE 2005-21. Universidad de los Andes. Bogotá.

Millar, R. (1995). Microeconomía. México: McGraw-Hill.

Pérez Herrera, A. (2004). Análisis del mercado de energía colombiano y estudio de sus posibles modificaciones. Departamento de Ingeniería, Universidad de los Andes. Bogotá.

Poveda, G. (2004). La hidroclimatología de Colombia: Una síntesis desde la escala inter-decadal hasta la escala diurna. Revista de la Academia Colombiana de Ciencias Exactas, Física y Naturales, 38(146).

Rojas Fernández, R. (2001). Bolsa de Energía en el SING. Simulación vía teoría de juegos. Pontificia Universidad Católica de Chile.

Thompson, L. (1993). Reconstructingthe paleo ENSO records from tropical and sub tropical ice cores. Bull. Inst. Fr. Études Andines.

Timmermann, J. et al. (1999). Increased El Nino Frequency in a Climate Model Forced by Future Greenhouse Warming. Nature, 398. 
Trenberth, K. (Ed.). (1993). Climate system modeling. Cambridge University Press, Cambridge, UK.

Trenberth, K. y Hoar, T. (1997). El Niño and climate change. Geophysical Research Letters, vol. 24.

UNAM. (2007). Cambio climático global y El Niño: Expectativas para el 2007. Boletín 3. Centro de Ciencias de la Atmósfera, Universidad Nacional Autónoma de México. www.atmosfera.unam.mx

UPME. (2004). Una visión del mercado eléctrico colombiano. Bogotá.

Varian, H. (1998). Análisis macroeconómico. Barcelona: Antoni Bosh Editor.

Vega Redondo, F. (2000). Economía y juegos. Barcelona: Antoni Bosh Editor. 